\title{
How the configurations of job autonomy, work-family interference, and demographics boost job satisfaction: an empirical study using fsQCA
}

\author{
Jing $\mathrm{Wu}^{1}$ (D) Jianan $\mathrm{Zhou}^{1}$
}

Received: 6 October 2019 / Revised: 23 September 2020 / Accepted: 2 October 2020 /

Published online: 16 October 2020

(c) Springer Nature Limited 2020

\begin{abstract}
In the gig economy era, job characteristics that affect employees' job satisfaction have undergone significant changes. However, this has not been studied adequately in the context of Asia. This study applies the job demand-resource model to understand the effect of job autonomy and work-family interference on the job satisfaction of full-time and part-time employees in China, while considering the role of demographics. A total of 415 respondents were analyzed through fuzzy set qualitative comparative analysis. The results show that the employees' demographics have a corrective effect on the impact of job characteristics and job satisfaction. This study also identifies six causal conditions for the high job satisfaction of full-time employees and three causal conditions for part-time employees. Our research finds that full-time employees need high job autonomy, while part-time employees need low work-family interference. The results provide guidelines for managers to redesign jobs in the era of the gig economy.
\end{abstract}

Keywords Job autonomy · Work-family interference $\cdot$ Job satisfaction · Job demand-resource model $\cdot$ China fuzzy set qualitative comparative analysis

\section{Introduction}

Job satisfaction is an individual's emotional commitment to his or her organizational role. From research and practice perspective, the most significant employee attitude is job satisfaction. Increasing the degree of employees' job satisfaction is crucial for performance improvement of enterprises. To understand the factors that lead

Jing Wu

JeanWu126@163.com

Jianan Zhou

zjncf76@aliyun.com

1 School of Economics and Management, Southwest Jiaotong University, No.111, North Erhuan Road, Chengdu 610031, China 
to people's satisfaction with their jobs, the nature of the work itself should be the first focus of practitioners (Saari and Judge 2010). Previous studies based on the job characteristics model have found that job autonomy has positive, significant correlation with job satisfaction (Federici 2013). Hence, it is reasonable to assume that job autonomy, as a job resource, is key to the success of an organization, and employees who have more autonomy in their work are more likely to experience job satisfaction as they can freely make their own decisions. When employees have more autonomy in their work, they can handle work stress better (Schiff and Leip 2019). Further, job satisfaction often surveyed in the context of the results of work-family conflicts (WFCs; Grandey et al. 2005). This type of conflict causes employees to experience stress, which weakens their evaluations of their jobs and leads to decreased job satisfaction (Zhao and Namasivayam 2012). The job demand-resource (JDR) model is a robust framework in understanding that stress is due to an imbalance between demands on the individual and the resources that he or she has to deal with those demands (Bakker and Demerouti 2007; Demerouti and Bakker 2011). In particular, job autonomy and work-family interference have been used as a variable for job resource and job demand, respectively, and have been demonstrated to directly or indirectly affect job satisfaction.

According to Bakker et al. (2011), the JDR model could be applied effectively to the work-family interface, helping us understand specific job designs that can promote or prevent work-family interference. Although the primary goal of the JDR model is to handle work and family responsibilities better, significant inconsistencies exist in the practical effectiveness of the space-time flexibility practices of work-life balance (Allen and Shockley 2009). For example, during the COVID19 outbreak in China in early 2020, many companies utilize home offices, staggered peak, flexible work, and online offices to facilitate the resumption of work. It is believed that flexible working would ease work-family interference and lead to higher job satisfaction of employees. However, several people feel that this type of working arrangement, being preoccupied with the family, can lead to physical and mental exhaustion. Although job satisfaction may be one of the most popular research topics in the organizational behavior literature, the actual factors that drive employee satisfaction remain unclear (Westover and Taylor 2010). Previous studies provide only a partial view on job satisfaction as they often focus on the one-toone relationship between an antecedent condition and job satisfaction, and only few studies focus on a global view to demonstrate how different factors simultaneously affect job satisfaction (Alegre et al. 2016; Chang and Cheng 2014). Although several studies have presented the collective effect of different employee relationships on job satisfaction, demographics and the nature of work, especially in Asia, are not considered.

To address the research gap, we conducted our study on employees of digital platforms in China. With the prevalence of digital economic platforms, two main types of employees have appeared on the market; the first one is full-time employees with long-term employment commitments, and the other one is part-time employees. They do not contract on any platform but can use his or her spare time to take orders from several platforms. Hence, discussing the job satisfaction of fulltime and part-time employees separately is logical. In this study, we used fuzzy 
set qualitative comparative analysis (fsQCA) to explore the coexistence of work autonomy, work-family interference, and demographics when different types (i.e., full time or part time) of employees showed high job satisfaction. In particular, this research design highlights the working characteristics of employees in the new era. The main contributions of this study are as follows. First, we used Chinese data as as an example in the context of Asian culture, which improved the application of the JDR model in the relationships of job satisfaction. Second, we added several demographics in the survey to accurately define the combination of job characteristic variables that might result in job satisfaction to achieve the purpose of correcting the results. Third, the results can be applied more accurately when the difference between full-time and part-time employees is distinguished, which can help us propose more targeted work design suggestions based on the job characteristics of different employees.

\section{Literature review and hypotheses}

\section{Job autonomy}

Job autonomy refers to the degree to which employees can make independent decisions independently and have autonomy in planning and executing tasks (Hackman and Oldham 1976; Morgeson and Humphrey 2006). It also refers to a job characteristic allowing employees the freedom to make decisions about their work (Karasek et al. 1998), including the degree of individual control over when, where, and how they work (Hackman and Oldham 1980). For many years, autonomy has been the focus of various theories of job design (e.g., Hackman and Oldham's job characteristics theory 1980, Karasek's job demand-control theory 1979, Bakker and Demerouti's job demand-resource theory 2007). Based on the job characteristic model (Hackman and Oldham 1976, 1980), job autonomy is a core job characteristic that can generate a psychological state of experienced responsibility, which can consequently lead to the right work attitude and behavior (Deci et al. 2017). However, in the new era, job autonomy not only refers to the ability of employees to decide the time, place, and duration of daily work but also includes the freedom of work arrangement. Thus, this study measures job autonomy based on two aspects: job autonomy in time (JAT) and job autonomy in arrangement (JAA).

\section{Work-family interference}

A balance between work and life domains is "the satisfaction and good functioning at both work and family with minimal role conflict" (Clark 2000). However, these domains may sometimes conflict, especially when the demands of one domain do not comply with those of another domain. Based on the role theory, WFC is a form of inter-role conflict, and role pressures from the work-family interface are contradictory in several ways (Greenhaus and Beutell 1985). Research has identified various types of conflict, including WFC and family-work conflict (FWC). The former 
refers to the work domain that impedes the performance of family roles, whereas the latter refers to the family domain that hinders the performance of work roles (Carr et al. 2008). Therefore, this study measures the work-family interference from two aspects: WFC and FWC.

Currently, most of the empirical evidence regarding the work-family interface has been found in the context of Western countries that share key characteristics of cultural individualism instead of collectivism. As many Asian countries have experienced relatively fast economic development since the 1970s, these issues have also been a relevant field of study within Asian societies recently (Sakamoto and Spinks 2008). The relationship between work and family is significantly influenced by social values, beliefs, and norms, and different cultural backgrounds have various forms of expression and socio-psychological significance. Cultural contexts (such as power distances, and individualism-collectivism tendencies) have a significant impact on the relationship between WFC and work attitudes ( $\mathrm{Su}$ et al. 2019). Therefore, the findings from individualistic societies may not apply to collectivistic societies (Lim et al. 2012). In an individualistic society, people care more about themselves and their families. Thus, the relationship between work and family is competitive, zero-sum relationship, and WFCs are a form of sacrifice to family interests (Wang and He 2008). However, in a collectivist society, work is not only an individual's own business but also a way to enhance the overall interests of the family. Hence, people work to achieve family happiness, and the relationship between work and family is a non-competitive, non-zero-sum relationship. Unlike employees with collectivist tendencies, employees with individualist tendencies highly generate more negative work attitudes owing to offending factors that might cause damage to family interests when they experience WFCs. For collectivist countries such as China, research on the work-family interface began in the early twentieth century. At present, it mainly focuses on the differences between the impact of work-family interference on outcome variables under the cultural differences between China and the West and in some professional fields (Liu et al. 2013; Su et al. 2019; Yang et al. 2015).

\section{Job autonomy, work-family interference, and job satisfaction}

Job satisfaction is vital structure discussed in organizational culture and especially in the context of organizational success. Job satisfaction is a broad concept that refers to the overall work attitude. Job satisfaction in the literature is most commonly explained by Hackman and Oldham's (1976) job characteristics theory, which holds that job satisfaction will increase when intrinsic motivation related to work exists. Karasek (1979) emphasized that employees' work pressure comes from job characteristics, including job demand and job control. These two factors comprise the earliest model of job characteristics, namely, the job demand-control model (JDC model). Job demands are psychological demands on employees in the form of time pressure, attention demands, and workload. Job control refers to the control employees have over their tasks and behaviors, which arises from the participation of decision-making in work to improve their autonomy. To compensate 
for the shortcomings of the JDC model, Demerouti et al. (2001) proposed the job demand-resource model (JDR model).

The JDR model assumes that each occupation has characteristics related to employee well-being, which can be divided into job demands or job resources. Job demands refer to the physiological, psychological, social, and organizational requirements of work and require continuous physical or mental (cognitive and emotional) efforts or skills to cope with, such as task interruption, workload, role ambiguity, and WFC (Bakker and Demerouti 2007). Although most previous studies (Geurts et al. 2009; Bakker et al. 2011) have considered WFC as an outcome variable of job demands, for FWC, another direction of work-family interference, few studies explicitly use the job demands and job resources perspectives to determine the determinants of domestic violence. This could be because early studies tend to use family-related characteristics as predictors of FWC (Frone et al. 1992). However, many empirical studies show that to completely understand the relevant factors of FWC, the job characteristics cannot be ignored. For example, studies have shown that the subjective measures of job stress and job demands are associated with greater FWC (Nomaguchi 2012). The previous studies have found that income, job opportunity, support supervisors, scheduling flexibility, and task significance are associated with lower WFC as work hours and job status remain the same (Kelly et al. 2014; Schieman and Glavin 2008). Quantitative research shows that income, supervisor support, task significance, and scheduling flexibility are correlated with lower FWC (Nomaguchi 2012). The link between job resources and FWC should be reviewed while controlling for work hours and occupational status. We considered FWC as a job demand variable because WFC and FWC should be regarded as an integration, as a reciprocal relationship exists between them. The rationale for this relationship is based on the assumption that if one's work-related problem and responsibilities begin to interfere with the accomplishment of family-related obligations, these unfulfilled family obligations may begin to interfere with one's day-today functioning at work, and vice versa. This reciprocal relationship has been confirmed by Schaubroeck and Ganster (1991) and Frone et al. (1992). Job resources include physiological, psychological, social and organizational resources, and their primary role is to achieve work goals, reduce job demands, or promote personal growth and development, such as job autonomy and social support (Demerouti et al. 2001). Employees feel greater satisfaction when they are independent and free to make work-related decisions. Currently, job autonomy has conceptualized as a job characteristic that can bring positive results ( $\mathrm{Lu}$ et al. 2017). However, when competing demands do not balance employees' work and family, they may feel job dissatisfaction. Job autonomy has a positive effect on job satisfaction, while WFC has a negative mediating effect on the relationship between job autonomy and job satisfaction (Gözükara and Çolakoğlu 2016). Therefore, when job autonomy and WFC exist simultaneously, the satisfaction configuration generated is more in line with the actual situation faced by modern work.

Based on the job demand-resource model, job autonomy helps employees minimize conflicts caused by competing responsibilities from their work and family life (Korunka and Kubicek 2017; Ng and Feldman 2015). Those who can decide on their work hours, for example, by finding childcare support, are more capable 
of managing their work and family responsibilities. Therefore, job resources reduce the adverse effect of job demands on burnout, where job resources minimize work demands and the related burnout (Schaufeli and Taris 2014). The autonomy in arrangement can be regarded as an environmental relationship, which provides employees more autonomy in deciding when to complete the work in the field of resources. It may better enable employees to manage the WFC caused by the tax situation (Ten Brummelhuis and Bakker 2012). Although WFC may be unavoidable, job autonomy in arrangement, as a resource, can provide employees with flexibility and control. Hence, they can better manage their impact on their emotional state and relieve the emotional exhaustion caused by the WFC. Therefore, we hope to regulate the negative correlation between WFC and emotional exhaustion through job autonomy. In this way, employees who experience WFC but have high job autonomy in arrangement incur less emotional exhaustion. As fixed 9-to-5 working hours and family schedule requirements (such as school pickup times) are often incompatible, controlling work hours may help resolve such conflicts (Craig and Powell 2012). Consequently, several studies have shown that schedule control can ease employees' WFC (Allen et al. 2013; Kelly et al. 2014). With the increase of working hours and two-earner families, job autonomy may become necessary for balancing family and work (Wegman et al. 2018). Based on the above analysis, we assume the following:

Hypothesis 1 The coexistence of job autonomy and work-family interference has an impact on job satisfaction.

\section{Influence of demographics}

Previous research has also found that some demographic variables play an essential role. Chinese scholar Ke Jianglin and his collaborators explored the impact of demographic factors on job satisfaction of R\&D personnel. They found that gender, marital status, age, education level, company seniority, and income level have varying degrees of impact on job satisfaction (Ke et al. 2009). Demographic variables not only affect job satisfaction but they are also particularly prominent in the work-family interference. As women still appear to be responsible for most of the housework and childcare in today's society, investigating the moderating role of gender in the strength of the relationship between FWC and job performance deserves future research attention (Karatepe and Kilic 2007). Byron (2005) analyzed 60 articles and found that men's WFC was significantly higher than that of women, while women's FWC was significantly higher than that of men. From a scarcity perspective, work-family interference might have different directions for men and women owing to traditional gender roles. Traditional caregiving roles expect women to devote relatively more attention to the family (Eagly 1987), suggesting that work should be a more significant source of conflict for women than men. Previous studies have supported the view of "breadwinning men and homemaking women" in the traditional social role theory. In other words, male employees face higher job expectations and are thus more likely to feel WFC. Moreover, when female employees face higher family expectations, 
they are more likely feel family interference in work. Finally, we build theory by identifying the omitted mediators that explain the relationship between gender and work-family interference, given evidence that existing theoretically specified mechanisms are insufficient for describing this relationship. Overall, we found more evidence for similarities rather than differences in the degree of work-family interference experienced by men and women (Shockley et al. 2017). Empirical results on whether there are gender differences in work-family interference are equally equivocal. Hence, we decided to examine the role of gender.

In addition to gender, age is also an essential factor. Studies show that as a woman's working-age increases, their family responsibilities also continue to increase and even exceed that of men. Thus, extra effort will be required to perform family roles; thus, they may be subjected to higher levels of WFC (Arun et al. 2004). O'Laughlin and Bischoff (2005) found that for nontenured college scientific researchers in the United States, as the working-age continues to increase, if the timeline for childrearing is not delayed, the increase of female's WFC will be significantly higher than that of men. Chinese scholars Zhao and Gao examined a sample of 500 new-generation knowledge workers from high-tech companies and used a univariate multivariate ANOVA to reveal the demographic differences in work-family interference. The results showed significant differences in gender and seniority exist in work-family interference of new-generation knowledge workers (Zhao and Gao 2014). Further, the impact of working hours needs attention. Although we found evidence that work autonomy acts as a mediator between gender and WFC, other factors seem to be required to explain why the WFC has only negligible gender differences (Shockley et al. 2017). As the working hours of part-time and full-time employees are different, the degree of job autonomy is also indirectly reflected. Therefore, impact in part-time and full-time employees is best examined separately when considering the effect of working hours. Studies have shown that the older the full-time frontline employees of hotels are, the more serious the WFC becomes for them, as they do not seem to have a heavy workload and have irregular and inflexible work arrangements. Because they work longer in the workplace, they are expected to handle some work-related tasks more effectively, which leads to overwork (Karatepe and Kilic 2007). To minimize WFCs, people may also make a tradeoff between work and family investment to achieve a balance between the two. By summarizing the existing research, we found that these demographic variables not only have an impact on job characteristics and job satisfaction but also have interactive effects between the variables. Hence, the influence of the combined configuration of demographic variables and job characteristic variables on the result variable (job satisfaction) should be investigated. Based on the above analysis, we assume the following:

Hypothesis 2a Demographic variables changed the effect of the coexistence of job autonomy and work-family interference on the job satisfaction of full-time employees.

Hypothesis 2b Demographic variables changed the effect of the coexistence of job autonomy and work-family interference on job satisfaction of part-time employees. 


\section{Research method}

\section{Data sources}

The data used in this paper were collected from the Chinese General Social Survey (CGSS) in 2015, which is the first nationwide comprehensive and continuous large-scale social survey project in China and implemented by the Renmin University of China in collaboration with academic institutions across the country. In 2015 , the CGSS project survey covered 478 villages and communities in 28 provinces/ cities/autonomous regions nationwide. The survey was conducted from July to October 2015. According to statistics, 10,968 valid questionnaires were completed. The data of 2015 used in this paper is currently the latest data published online, which ensures the timeliness of our data. The objects of this study are full- and part-time workers aged 18-60. The survey variables were taken from the core module (part A) of the CGSS project and the work module (part D) of the International Social Survey Programme (ISSP). After deleting samples with missing demographic data or other variables essential to this study, a total of 359 samples of full-time employees and 56 samples of part-time employees involved the variables being studied in this paper.

\section{Variable description}

The demographic variables in this paper are from the core modules (part A), including gender (GEN), age (AGE), weekly working hours (WWH), annual total labor income (INC), and company type (COT). The antecedent variables were derived from the work module (part D) and included job autonomy (AUT) and work-family interference (WFI). The outcome variable job satisfaction (SAT) is derived from the work module (part D). Table 1 presents specific variable measurement methods and assignment instructions. According to the demographic variables, the sample description statistics of this study are shown in Table 2 .

\section{ANOVA in company type}

As the sample of this study comes from various sources, to distinguish the differences in job autonomy, work-family interference, and job satisfaction among employees of different types of companies, we used ANOVA to explore. We found that for full-time employees, significant differences exist in the perceived job autonomy in time and job satisfaction for different company types. Among them, self-employed workers have significantly higher job autonomy in time compared to employees who work in the party and government institutions, enterprises, and public institutions. Moreover, those in enterprises have significantly higher job autonomy in time than employees of public institutions. On job satisfaction, employee satisfaction in the party and government institutions, public institutions, and social organizations or residents/village committees is 


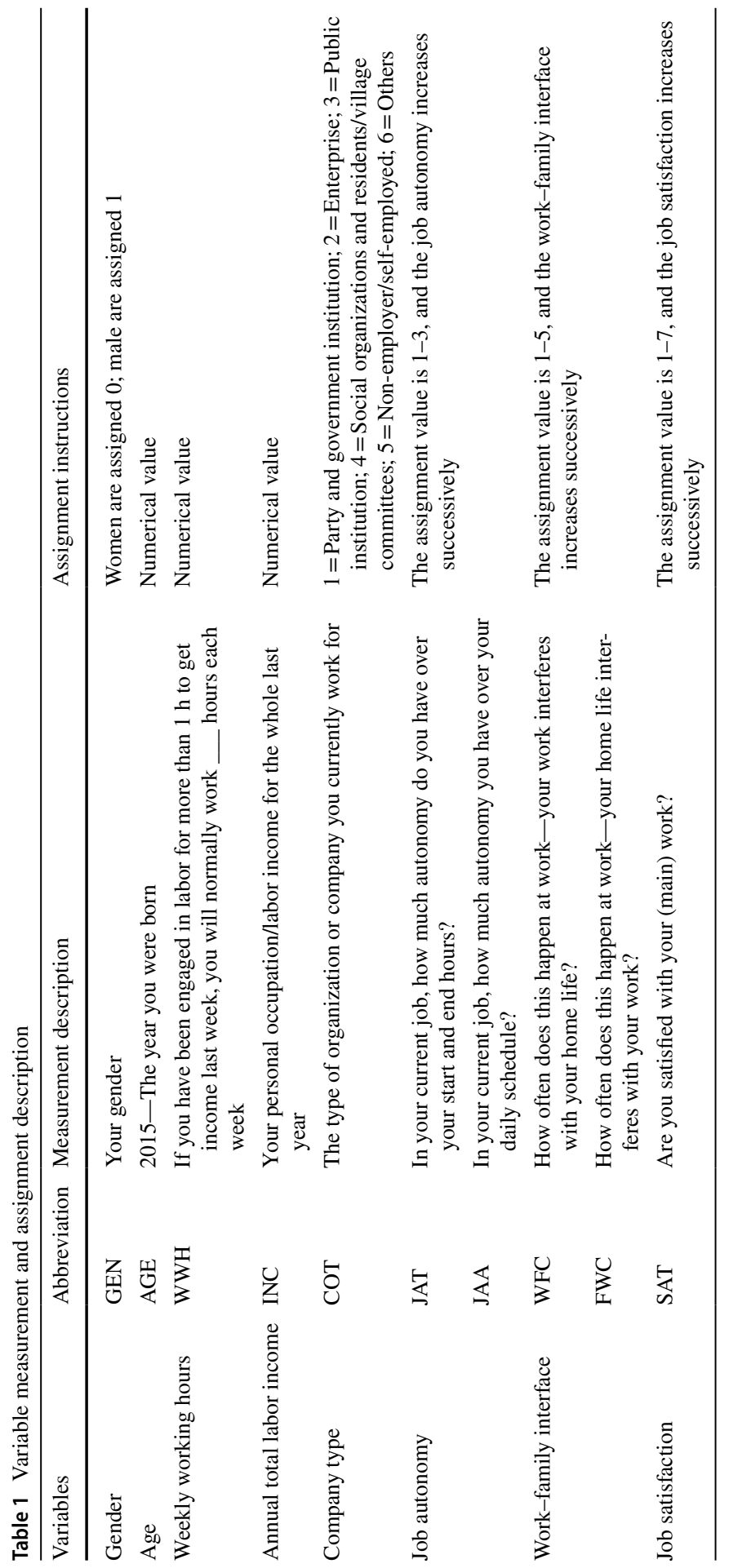


Table 2 Demographic profile respondents

\begin{tabular}{|c|c|c|c|c|c|}
\hline \multicolumn{2}{|c|}{ Variables } & \multicolumn{2}{|c|}{$\begin{array}{l}\text { Full-time employees } \\
(N=359)\end{array}$} & \multicolumn{2}{|c|}{$\begin{array}{l}\text { Part-time employees } \\
(N=56)\end{array}$} \\
\hline & & Number & Proportion (\%) & Number & Proportion $(\%)$ \\
\hline \multirow[t]{2}{*}{ GEN } & Male & 165 & 46 & 30 & 53.6 \\
\hline & Female & 194 & 54 & 26 & 46.4 \\
\hline \multirow[t]{4}{*}{ AGE } & $18-23$ & 27 & 7.5 & 4 & 7.1 \\
\hline & $24-30$ & 71 & 19.8 & 4 & 7.1 \\
\hline & $31-40$ & 123 & 34.3 & 12 & 21.4 \\
\hline & $41-60$ & 138 & 38.4 & 36 & 64.3 \\
\hline \multirow[t]{4}{*}{ WWH } & $40 \mathrm{~h}$ and less & 169 & 47.1 & 16 & 28.6 \\
\hline & $41-50 \mathrm{~h}$ & 69 & 19.2 & 8 & 14.3 \\
\hline & $51-60 \mathrm{~h}$ & 84 & 23.4 & 20 & 35.7 \\
\hline & $60 \mathrm{~h}$ and more & 37 & 10.3 & 12 & 21.4 \\
\hline \multirow[t]{5}{*}{ INC } & Less than 50,000 & 239 & 66.6 & 49 & 87.5 \\
\hline & $50,000-100,000$ & 105 & 29.2 & 6 & 10.7 \\
\hline & $110,000-200,000$ & 14 & 3.9 & 0 & 0 \\
\hline & $210,000-300,000$ & 1 & 0.3 & 1 & 1.8 \\
\hline & More than 300,000 & 0 & 0 & 0 & 0 \\
\hline \multirow[t]{6}{*}{ COT } & Party and government institution & 20 & 5.6 & 0 & 0 \\
\hline & Enterprise & 198 & 55.2 & 17 & 29.4 \\
\hline & Public institution & 74 & 20.6 & 0 & 0 \\
\hline & $\begin{array}{l}\text { Social organizations and residents/ } \\
\text { village committees }\end{array}$ & 17 & 4.7 & 0 & 0 \\
\hline & Non-employer/self-employed & 37 & 10.3 & 34 & 60.7 \\
\hline & Others & 13 & 3.6 & 5 & 8.9 \\
\hline
\end{tabular}

significantly higher than that of employees in enterprises. For part-time employees, significant differences exist in perceived job autonomy in time and FWC for different types of companies. Self-employed workers have significantly higher job autonomy in time than enterprise employees. In contrast, the FWCs of employees

Table 3 ANOVA results

\begin{tabular}{|c|c|c|c|c|}
\hline \multirow[t]{2}{*}{ Variables } & \multicolumn{2}{|c|}{$\begin{array}{l}\text { Full-time employees } \\
(N=359)\end{array}$} & \multicolumn{2}{|c|}{$\begin{array}{l}\text { Part-time employees } \\
(N=56)\end{array}$} \\
\hline & $F$ & Significance & $F$ & Significance \\
\hline JAT & 5.262 & 0.000 & 4.374 & 0.017 \\
\hline JAA & 0.773 & 0.570 & 2.407 & 0.100 \\
\hline WFC & 1.011 & 0.411 & 1.726 & 0.188 \\
\hline FWC & 1.566 & 0.169 & 6.021 & 0.004 \\
\hline SAT & 5.193 & 0.000 & 0.564 & 0.572 \\
\hline
\end{tabular}


in other companies are significantly higher than those in enterprises and selfemployed workers. The main results are summarized in Table 3.

\section{Findings}

As a set of theoretical methods, fsQCA is used explicitly for case-oriented exploration of social science phenomena. From the traditional perspective of quantitative analysis, the idea of quantitative research is to set both the cause and result variables and then verify the significance of the two at the statistical level. One of the main "either-or" assumptions is that causative variables are either correlated or not correlated, but this assumption is strictly against the real environment. Although many symmetric correlations exist in our lives, a number of asymmetric set relationships are also present. Unlike regression analysis, the nonparametric set approach makes sample representativeness less of a concern because researchers do not assume data from a given probability distribution. Thus, without a new empirical approach to the concept of causal complexity (relations in set theory), the understanding of complementarity and equilibrium cannot be further developed. fsQCA provides a systematic method for the calibration and quantification of qualitative data sets (fuzzy membership assignment) (Woodside et al. 1999). QCA allows for the exploration of the relationships between variables. This approach has some compelling advantages in analyzing asymmetric relationships as it allows for exploring how factors can be combined into configurations of necessary and sufficient conditions to form the basis of results (Rihoux 2009).

\section{Data and calibration}

To transform the conventional scale and interval scale variables into fuzzy sets, calibrating them so that they match or are consistent with external standards is necessary. These variables correspond to the three qualitative breakpoints that constitute the fuzzy sets: the threshold of full membership (fuzzy score=0.95), the threshold of full non-membership (fuzzy score $=0.05$ ), and the crossover point (fuzzy score $=0.5$ ). Based on this, the threshold value of the involved variables is set in this study. For example, job autonomy is a three-point scale. In this study, " 3 " is defined as full membership, " 2 " as crossover point, and " 1 " as full non-membership. Based on the setting of these three thresholds, the fuzzy calibration function in fsQCA software is used to convert these values into 0-1 fuzzy scores. Calibration procedure standards for all variables are shown in Table 4.

\section{Univariate consistency and necessity analysis}

In a qualitative comparative analysis, consistency and coverage are critical indicators. They can be used to judge whether there is a relationship between the antecedent configurations and the results. Consistency refers to the extent to which all cases included in the analysis share a given condition (or combinations 
Table 4 Calibrate program assignment standard summary

\begin{tabular}{llll}
\hline Variables & Threshold value & & \\
\cline { 2 - 4 } & Full membership & Crossover point & Nonmembership \\
\hline GEN & 1 & 0.5 & 0 \\
AGE & 60 & 40 & 18 \\
WWH (full-time/part-time) & $98 / 94$ & $46 / 54$ & $4 / 25$ \\
INC (full-time/part-time) & $200,000 / 100,000$ & $45,000 / 26,000$ & $3000 / 5000$ \\
AUT & 3 & 2 & 1 \\
WFI & 5 & 3 & 1 \\
SAT & 7 & 5 & 3
\end{tabular}

of conditions), which leads to the outcome. Coverage is the extent to which these given conditions (or combinations of conditions) explain the results. If condition $X$ is necessary condition for result $Y$, then the set corresponding to $Y$ is a subset of the set corresponding to $X$, and the value of its corresponding necessity consistency index should be greater than 0.9 . Otherwise, if the necessity consistency index is less than 0.9 , then $X$ cannot be regarded as a necessary condition for $Y$.

In this study, several demographic variables, such as GEN, AGE, WWH, and INC, as well as the antecedent conditions of AUT and WFI to generate job satisfaction, were analyzed. The results in Table 5 show that the necessary consistency of a single variable is less than 0.9 except for the AGE of part-time workers, which is not enough to constitute the necessary condition of job satisfaction. Basically, except for the older part-time workers who can get higher job satisfaction, none of the other variables can independently predict job satisfaction.

Table 5 Necessary conditions analysis for the outcome

\begin{tabular}{llllll}
\hline $\begin{array}{l}\text { Antecedent } \\
\text { variables }\end{array}$ & \multicolumn{2}{l}{ Full-time employees } & & \multicolumn{2}{l}{ Part-time employees } \\
\cline { 2 - 3 } & Consistency & Coverage & & Consistency & Coverage \\
\hline GEN & 0.542567 & 0.519195 & 0.553981 & 0.380537 \\
AGE & 0.857547 & 0.613611 & 0.933073 & 0.469980 \\
WWH & 0.754206 & 0.678394 & & 0.745970 & 0.577752 \\
INC & 0.664491 & 0.761330 & & 0.665852 & 0.625516 \\
JAT & 0.315858 & 0.793533 & & 0.648266 & 0.554071 \\
JAA & 0.603341 & 0.779716 & 0.663898 & 0.556967 \\
WFC & 0.484179 & 0.727135 & & 0.489985 & 0.621053 \\
FWC & 0.402813 & 0.794058 & 0.461651 & 0.695876 \\
\hline
\end{tabular}


Table 6 Job characteristics configurations predicting job satisfaction

\begin{tabular}{lllll}
\hline Variable & A1 & A2 & A3 & A4 \\
\hline JAT & $\bullet$ & $\otimes$ & $\otimes$ & $\otimes$ \\
JAA & $\otimes$ & $\bullet$ & $\otimes$ & $\bullet$ \\
WFC & $\otimes$ & $\otimes$ & $\otimes$ & $\bullet$ \\
FWC & $\otimes$ & $\otimes$ & $\bullet$ & $\bullet$ \\
CS & 0.817 & 0.811 & 0.832 & 0.909 \\
RCV & 0.283 & 0.532 & 0.348 & 0.276 \\
UCV & 0.029 & 0.191 & 0.087 & 0.013 \\
SCS & 0.786 & & & \\
SCV & 0.673 & & & \\
\hline
\end{tabular}

"•" Represents the condition exists, " $\otimes$ " represents the condition does not exists, "blank" represents whether the condition exists or not in the configuration

$C S$ Consistency, $R C V$ Raw Coverage, $U C V$ Unique Coverage, i.e. coverage independently interpreted by the configuration and not coinciding with other configurations of the same interpreted result, SCS Solution Consistency, SCV Solution Coverage

\section{Results from the fsQCA}

The results in Table 6 support H1: the coexistence of job autonomy and work-family interference has an impact on job satisfaction. A total of four combined configurations affect job satisfaction. The solution coverage is 0.673 , and the consistency of the solution is 0.786 , indicating that the four configurations explain a significant proportion of employees' job satisfaction. The most explainable configuration is $\mathrm{A} 2: \sim \mathrm{JAT} * \mathrm{JAA} * \sim \mathrm{WFC} * \sim \mathrm{FWC} \leq \mathrm{SAT}$, and the unique coverage rate is 0.191 , and the consistency is 0.811 . It means that in the case of low job autonomy in time and low work-family interference, higher job autonomy in arrangement can improve employees' job satisfaction. Another configuration worth explaining is A1: JAT $* \sim \mathrm{JAA} * \sim \mathrm{WFC} * \sim \mathrm{FWC} \leq \mathrm{SAT}$, the unique coverage rate is 0.029 , and the consistency is 0.817 . It indicates that higher job autonomy in time can improve employees' job satisfaction when the job autonomy in arrangement and the work-family interference are both low. Notably, the total interpretation of configurations A3 and A4 reached $10 \%$. From the results of these two configurations, we can see the particularity of FWC. That is, whether the job autonomy in arrangement and WFC is high or low, job satisfaction is high even under low job autonomy situations in time and high FWC. This indicates that there may be other antecedent conditions affecting the results.

The results in presented in Table 7 support H2a: demographic variables changed the effect of the coexistence of job autonomy and work-family interference on job satisfaction of full-time employees. Table 7 shows that for full-time employees, demographic variables have a corrective effect on the structural configuration of job autonomy and work-family interference. In summary, Table 7 shows six configurations that improve job satisfaction for full-time employees. The coverage rate of the overall configuration is 0.456 , and the overall consistency is 0.895 (higher 
Table 7 Configurations of demographics via job autonomy and work-family interference predicting full-time employees' job satisfaction

\begin{tabular}{lllllll}
\hline Variable & B1 & B2 & B3 & B4 & B5 & B6 \\
\hline GEN & $\otimes$ & $\bullet$ & $\bullet$ & $\bullet$ & $\otimes$ & $\bullet$ \\
AGE & $\bullet$ & $\bullet$ & $\bullet$ & $\otimes$ & $\bullet$ & $\bullet$ \\
WWH & $\otimes$ & $\bullet$ & $\otimes$ & $\bullet$ & $\bullet$ & $\bullet$ \\
INC & $\otimes$ & $\bullet$ & $\bullet$ & $\otimes$ & $\otimes$ & $\bullet$ \\
JAT & $\bullet$ & $\otimes$ & $\otimes$ & $\bullet$ & $\otimes$ & $\bullet$ \\
JAA & $\bullet$ & $\otimes$ & $\bullet$ & $\bullet$ & $\bullet$ & $\bullet$ \\
WFC & $\otimes$ & $\otimes$ & $\otimes$ & $\otimes$ & $\bullet$ & $\otimes$ \\
FWC & $\otimes$ & $\otimes$ & $\otimes$ & $\otimes$ & $\bullet$ & $\otimes$ \\
CS & 0.905 & 0.902 & 0.911 & 0.912 & 0.931 & 0.906 \\
RCV & 0.102 & 0.244 & 0.210 & 0.100 & 0.129 & 0.119 \\
UCV & 0.029 & 0.071 & 0.026 & 0.010 & 0.056 & 0.001 \\
SCS & 0.895 & & & & & \\
SCV & 0.456 & & & & & \\
\hline
\end{tabular}

"•" Represents the condition exists, " $\otimes$ " represents the condition does not exists, "blank" represents whether the condition exists or not in the configuration

$C S$ Consistency, $R C V$ Raw Coverage, $U C V$ Unique Coverage, i.e. coverage independently interpreted by the configuration and not coinciding with other configurations of the same interpreted result, SCS Solution Consistency, SCV Solution Coverage

than 0.786 in Table 5). In contrast, the unique coverage for configuration B2 was the highest and reached $7.1 \%$. As shown in B2, when job autonomy and WFC are low, those older (over 40 years old) male full-time workers who work for long hours every week and get more annual labor income had higher job satisfaction. The next highest interpretation is configuration B5, which reached 5.6\%. As shown in B5, when job autonomy in time is low and work-family interferences (including WFC and FWC) are high, older (over 40 years old) female full-time workers report higher job satisfaction scores. However, weekly working hours are longer, and their incomes are not high, which may occur due to their higher job autonomy in the arrangement. Another interesting configuration is B1. Although the explanation for B1 is not high, only $2.9 \%$, it reflects a relatively perfect combination of conditions. The B1 configuration results show that when job autonomy is high and work-family interference is low for older female full-time employees, job satisfaction can be high even with low annual incomes.

The results in Table 8 support H2b: demographic variables changed the effect of the coexistence of job autonomy and work-family interference on job satisfaction of part-time employees. Table 8 shows that for part-time employees, demographic variables have a correction effect on the structural configuration of job autonomy and work-family interference. Table 8 shows three configurations that improve the job satisfaction of part-time employees. The coverage of the overall configuration is 0.435 , and overall consistency is 0.851 (higher than 0.786 in Table 5). In contrast, configuration $\mathrm{C} 1$ reached the highest unique coverage, 18\%. As presented in $\mathrm{C} 1$, for older (over 40 years old) female part-time workers, even if they work longer 
Table 8 Configurations of demographics via job autonomy and work-family interference predicting part-time employees' job satisfaction

\begin{tabular}{llll}
\hline Variable & $\mathrm{C} 1$ & $\mathrm{C} 2$ & $\mathrm{C} 3$ \\
\hline GEN & $\otimes$ & $\bullet$ & $\bullet$ \\
AGE & $\bullet$ & $\otimes$ & $\bullet$ \\
WWH & $\bullet$ & $\otimes$ & $\bullet$ \\
INC & $\otimes$ & $\bullet$ & $\bullet$ \\
JAT & $\bullet$ & $\bullet$ & $\otimes$ \\
JAA & $\bullet$ & $\bullet$ & $\otimes$ \\
WFC & $\otimes$ & $\otimes$ & $\otimes$ \\
FWC & $\otimes$ & 0.870 & 0 \\
CS & 0.844 & 0.196 & 0.864 \\
RCV & 0.180 & 0.085 & 0.059 \\
UCV & 0.180 & 0.851 & \\
SCS & & 0.435 & \\
SCV & & $\otimes$ &
\end{tabular}

"•" Represents the condition exists, " $\otimes$ " represents the condition does not exists, "blank" represents whether the condition exists or not in the configuration

$C S$ Consistency, $R C V$ Raw Coverage, $U C V$ Unique Coverage, i.e. coverage independently interpreted by the configuration and not coinciding with other configurations of the same interpreted result, $S C S$ Solution Consistency, SCV Solution Coverage

time every week and earn less, as long as they have higher job autonomy and lower work-family interference, they can still perceive high job satisfaction. The second explanation rate is the configuration $\mathrm{C} 2$, which reached $8.5 \%$. As shown in $\mathrm{C} 2$, for younger (under 40 years old) male part-time workers, as long as they work less time every week and get higher incomes and perceive higher job autonomy and lower work-family interference, they can get higher job satisfaction scores. Further, one interesting configuration is C3. It has the same combined configuration with B2 (in Table 7). This shows that when job autonomy and work-family interference are both low, whether they are part-time or full-time employees, older male employees (over 40 years old) working long hours every week and get high annual labor incomes, leading to higher job satisfaction scores.

\section{Discussion}

This study aims to explore the relationships between full-time and part-time employees' demographics, job autonomy, work-family interference, and job satisfaction. Three hypotheses were proposed and verified. First, the theoretical propositions about job autonomy and work-family interference were proposed based on the JDR model, that is, the impact of the configuration of job autonomy and work-family interference on job satisfaction. We found that job autonomy (autonomy in time or autonomy in arrangement) can improve job satisfaction. Second, we discuss the corrective effect of the demographic variables of full-time and part-time employees on 
the impact of job characteristics on job satisfaction. We also found that owing to the different types of companies, employees' job autonomy, work-family interference, and job satisfaction show some differences. For full-time employees, the autonomy in time between employees of enterprises and self-employed are different, and job satisfaction between enterprises and the party and government institutions and public institutions are also different. The difference in job autonomy is closely related to the nature of work, but the difference in job satisfaction is closely related to the unique civil service system in China. Traditionally, the advantages of the "iron rice bowl" and "eating imperial grain" still play a role.

\section{Theoretical implications}

Our findings extend the JDR theory and make significant contributions to deepen the understanding of the nature of job autonomy and work-family interference and the internal relationship between job resources and job demands in the Asian context. First, this study enriches the application of job demand-resource theory in the Chinese context. Currently, job autonomy has been conceptualized as a job characteristic that can bring positive results ( $\mathrm{Lu}$ et al. 2017). Based on the logic of the job demand-resource model, we believe that providing employees with resources, such as job autonomy, may promote job satisfaction through work-family harmony (Chen et al. 2017). Previous studies demonstrated that employees with high levels of WFC have lower job satisfaction (Kossek and Ozeki 1998). With the increase in working hours and number of two-earner families, job autonomy may become a necessary condition for balancing family and work (Wegman et al. 2018). However, previous studies provide a partial view of job satisfaction since they usually focus on the oneto-one relationship between job demands-resources and job satisfaction, without considering the global view to show how different factors simultaneously affect job satisfaction. This study discussed the application of the JDR model to job satisfaction of full-time and part-time employees, respectively. The results of this study not only verify that the combined configuration of job resources and job demands has an impact on job satisfaction but also find the mitigating effect of job autonomy on the work-family interference.

Second, this study explores the combined configuration of job characteristics under different demographics and enriches the existing research results. Although some scholars have used the QCA method to explore the conditional configuration for improving job satisfaction, they mainly chose the antecedent conditions from the perspective of the organization or team, although their research also included job autonomy and WFC (Alegre et al. 2016; Chang and Cheng 2014). The difference of this study lies in the selection of antecedent conditions. We not only consider the job characteristics but also, most importantly, take the individual demographics into consideration and study the combined configuration of working conditions and individual conditions to boost job satisfaction. This is also more in line with the new era of career development, wherein careers are becoming more employee-centered (Kost et al. 2020). Three important conclusions can be drawn from this study's results, which are complementary to previous studies. First, for 
male employees, higher annual labor income is essential for improving job satisfaction. However, older male employees are more capable of withstanding the stress of long work hours. Consistent with the traditional view, men report higher levels of receiving work-related contact outside of work and work-home multitasking than women (Schieman and Glavin 2008). As a result, men are more able to bear work. In addition, we found that older full-time women are better at using job autonomy in arrangement to ease the work-family interference. Studies have found higher levels of WFC and FWC reported by married frontline employees (Karatepe and Kilic 2007). More definite boundaries could indicate that women are more psychologically present in the domain where they are physically located, regardless of the type of domain (Shockley et al. 2017). Consequently, women are better at handling work-family interference. Because of traditional breadwinner roles (Zuo 2004), the root of male conflict may be in the home (Gutek et al. 1991). Thus, for men, lower work-family interference is essential for improving job satisfaction. Finally, our research finds that full-time employees need more job autonomy, while part-time employees need work-family balance. It shows that full-time employees are better at handling WFCs than part-time employees.

\section{Practical implications}

Our findings provided several practical contributions to both managers and employees. First, establish a flexible and autonomous management environment. Enterprises should clarify strategic development goals, mission objectives, and work standards, strengthen the superior design, establish a flexible and autonomous management environment, and conscientiously implement the people-oriented concept in various tasks. It helps to reinforce employees' sense of corporate responsibility. Autonomy demand is increasingly becoming the dominant demand for a new generation of laborers. The results of several surveys show that the "post-90s" who entered the workplace in the past several years has a more prominent sense of autonomy than previous labor groups. These individuals want to perceive their existence in the flow of work by looking for challenging jobs that can promote their personal growth (Zhang et al. 2013). Self-determination theory believes that creating a work environment where employees feel supported and autonomous is not only an appropriate goal but will also bring more employee satisfaction. When individuals understand the value and purpose of their work, feel ownership and autonomy in performing their work, and receive precise feedback and support, they are likely to become more autonomous and perform better (Deci et al. 2017). Therefore, employees usually need autonomy in their work to achieve effective performance (Naqvi et al. 2013). Autonomy encourages employees to take pride in their work (Mehmood et al. 2012). As job autonomy encourages employees to believe that they can complete tasks, this can lead to improvement of performance (Saragih 2011).

Second, work and family interference can be resolved through job design. In the new management practice, with the advancement of information and communication technology (ICT), gig jobs will become increasingly popular. An increasing number of employers are moving away from fixed working schedules and choosing 
to work on-demand, on-time, and part-time jobs. Nonstandard work arrangements are becoming more common in the retail, catering, hotel, and cleaning industries, and even in some professional fields. To keep employees in good working conditions and maintain efficiency in this situation, space-time-based job design can be used as future job skills (Wessels et al. 2019). Flexible work can be achieve by having employees adjust their work needs to meet their families' needs (Golden 2001; Lott 2015). Therefore, job design with time and space flexibility will be necessary to respond to work and life requirements (Poelmans and Chenoy 2008). According to the JDR model, job resources reduce the adverse effects of job demands on burnout (Schaufeli and Taris 2014). Therefore, JDR's division of job resources and job demands helps us understand which specific job designs can promote or prevent work-family interference. Boundary theory is an emerging paradigm within the work-family literature. It provides a different lens to understand how individuals manage the interface between work and family by focusing on the boundary between work and family (Ashforth et al. 2000). Studies show that the clearer the role boundaries between work and family, the less the conflict between work and family (Padhi and Pattnaik 2017). Therefore, while having policy interventions to facilitate work-family balance, employees must be made aware about the consequences of unwarranted use. Additionally, the awareness that job resources and job demands can also happen simultaneously would provide practitioners additional tools to utilize job resources to achieve organizational goals strategically. Specifically, in the gig economy era, the redesign of gig work will become a new direction for managers and management scholars to think deeply about.

Third, incentives should vary from person to person and cannot be generalized. For example, for full-time employees, due to their fixed working time, job autonomy is in high demand, while for part-time employees, what needs to be solved is how to use the autonomic time to balance the relationship between work and family. Therefore, when motivating full-time and part-time workers, we should not only consider their individual needs but also consider the influence of other demographic variables. For example, for male employees, if they can be offered some welfare policies to reduce their work-family interferences, their work efficiency will be higher. For female workers, managers can motivate their commitment to the job by increasing their income levels.

\section{Limitations and directions for future research}

This study has limitations that can point to promising directions for future research. First, although this study extends the application of the JDR model in the Chinese context, it does not systematically compare the existing research in China and the West. In future studies, the research status of the JDR model in China and the West can be compared to find more research gaps caused by cultural differences and enrich the existing research on the JDR model in Asian culture. Second, the qualitative comparative analysis used in this study can only obtain the configurations antecedent of job satisfaction. The specific relationships between the variables need to be further verified by regression analysis, which provides a direction for 
future research on the relationship between job resources and job demands. Moreover, many variables for job resources and job demands exist. Except for the job autonomy and work-family interference involved in this study, more variables can be chosen, such as task interruption, workload, role ambiguity and other job demand variables (Bakker and Demerouti 2007), and social support and other job resource variables (Demerouti et al. 2001). Considering more variables in the model can make the results more consistent with the actual situation, and more valid results can be obtained. Third, due to data limitations, this study does not distinguish between industries. Although ANOVA is used to distinguish the types of employees' company, the differences in the industries cannot be represented well. Future research could complement industry data to refine the results.

Acknowledgements The authors would like to thank Professor Fang Lee Cooke and two anonymous reviewers for their insightful comments and suggestions. This work was partially supported by National Natural Science Foundation of China (CN) (Grant Number 71371155) and Humanities and Social Sciences Center, Ministry of Education (CN) (Grant Number 19XJA630006).

\section{References}

Allen, T. D., \& Shockley, K. (2009). Flexible work arrangements: Help or hype? In D. R. Crane \& E. J. Hill (Eds.), Handbook of families and work: Interdisciplinary perspectives (pp. 265-284). Lanham, MD: University Press of America.

Allen, T. D., Johnson, R. C., Kiburz, K. M., \& Shockley, K. M. (2013). Work-family conflict and flexible work arrangements: Deconstructing flexibility. Personnel Psychology, 66(2), 345-376.

Arun, S. V., Arun, T. G., \& Borooah, V. K. (2004). The effect of career breaks on the working lives of women. Feminist Economics, 10(1), 65-84.

Alegre, I., Mas-Machuca, M., \& Berbegal-Mirabent, J. (2016). Antecedents of employee job satisfaction: Do they matter? Journal of Business Research, 69(4), 1390-1395.

Ashforth, B. E., Kreiner, G. E., \& Fugate, M. (2000). All in a day's work: Boundaries and micro role transitions. Academy of Management Review, 25(3), 472-491.

Bakker, A. B., \& Demerouti, E. (2007). The job demands-resources model: State of the art. Journal of Managerial Psychology, 22, 309-328.

Bakker, A. B., ten Brummelhuis, L. L., Prins, J. T., \& van der Heijden, F. M. M. A. (2011). Applying the job demands-resources model to the work-home interface: A study among medical residents and their partners. Journal of Vocational Behavior, 79(1), 170-180.

Byron, K. (2005). A meta-analytic review of work-family conflict and its antecedents. Journal of Vocational Behavior, 67(2), 169-198.

Carr, J. C., Boyar, S. L., \& Gregory, B. T. (2008). The moderating effect of work-family centrality on work-family conflict, organizational attitudes, and turnover behavior. Journal of Management, 34(2), 244-262.

Chang, M. L., \& Cheng, C. F. (2014). How balance theory explains high-tech professionals' solutions of enhancing job satisfaction. Journal of Business Research, 67(9), 2008-2018.

Chen, S. C., Chiang, Y. H., \& Huang, Y. J. (2017). Exploring the psychological mechanisms linking work-related factors with work-family conflict and work-family facilitation among Taiwanese nurses. The International Journal of Human Resource Management, 28(4), 581-602.

Clark, S. C. (2000). Work/family border theory: A new theory of work/family balance. Human Relations, 53(6), 747-770

Deci, E. L., Olafsen, A. H., \& Ryan, R. M. (2017). Self-determination theory in work organizations: The state of a science. Annual Review of Organizational Psychology and Organizational Behavior, 4(1), $19-43$.

Demerouti, E., \& Bakker, A. B. (2011). The job demands-resources model: Challenges for future research. SA Journal of Industrial Psychology, 37(2), 1-9. 
Demerouti, E., Bakker, A. B., Nachreiner, F., \& Schaufeli, W. B. (2001). The job demands-resources model of burnout. Journal of Applied Psychology, 86(3), 499-512.

Eagly, A. H. (1987). Sex differences in social behavior: A social-role interpretation. Hillsdale, NJ: Erlbaum.

Federici, R. A. (2013). Principals' self-efficacy: Relations with job autonomy, job satisfaction, and contextual constraints. European Journal of Psychology of Education, 28(1), 73-86.

Frone, M. R., Russell, M., \& Cooper, M. L. (1992). Antecedents and outcomes of work-family conflict: Testing a model of the work-family interface. Journal of Applied Psychology, 77(1), 65-78.

Geurts, S. A. E., Beckers, D. G. J., Taris, T. W., Kompier, M. A. J., \& Smulders, P. G. W. (2009). Worktime demands and work-family interference: Does worktime control buffer the adverse effects of high demands? Journal of Business Ethics, 84(2), 229-241.

Golden, L. (2001). Flexible work schedules which workers get them? American Behavioral Scientist, 44(7), 1157-1178.

Grandey, A. A., Cordeiro, B. L., \& Crouter, A. C. (2005). A longitudinal and multi-source test of the work-family conflict and job satisfaction relationship. Journal of Occupational and Organizational Psychology, 78(3), 305-323.

Greenhaus, J. H., \& Beutell, N. J. (1985). Sources of conflict between work and family roles. Academy of Management Review, 10, 76-88.

Gutek, B. A., Searle, S., \& Klepa, L. (1991). Rational versus gender role explanations for work-family conflict. Journal of Applied Psychology, 76(6), 560-568.

Hackman, J. R., \& Oldham, G. R. (1976). Motivation through the design of work: Test of a theory. Organizational Behavior and Human Performance, 16(2), 250-279.

Hackman, J. R., \& Oldham, G. R. (1980). Work redesign. Reading, MA: Addison-Wesley.

Gözükara, İ, \& Çolakoğlu, N. (2016). The mediating effect of work family conflict on the relationship between job autonomy and job satisfaction. Procedia: Social and Behavioral Sciences, 229, 253-266.

Karasek, R. A. (1979). Job demands, job decision latitude, and mental strain: Implications for job redesign. Administrative Science Quarterly, 24(2), 285-308.

Karasek, R., Brisson, C., Kawakami, N., Houtman, I., Bongers, P., \& Amick, B. (1998). The Job Content Questionnaire (JCQ): An instrument for internationally comparative assessments of psychosocial job characteristics. Journal of Occupational Health Psychology, 3(4), 322-355.

Karatepe, O. M., \& Kilic, H. (2007). Relationships with supervisor support and conflicts in the workfamily interface with selected job outcomes of frontline employees. Tourism Management, 28(1), 238-252.

Ke, J. L., Sun, J. M., \& Ding, P. R. (2009). The determinants of R\&D worker's job satisfaction: A perspective of demography. Science of Science and Management of S\&T, 3, 194-198.

Kelly, E. L., Moen, P., Oakes, J. M., Fan, W., Okechukwu, C., Davis, K. D., et al. (2014). Changing work and work-family conflict: Evidence from the work, family, and health network. American Sociological Review, 79(3), 485-516.

Korunka, C., \& Kubicek, B. (2017). Job demands in a changing world of work. In C. Korunka \& B. Kubicek (Eds.), Job demands in a changing world of work: Impact on workers' health and performance and implications for research and practice (pp. 1-5). Cham: Springer.

Kossek, E. E., \& Ozeki, C. (1998). Work-family conflict, policies, and the job-life satisfaction relationship: A review and directions for organizational-human resources research. Journal of Applied Psychology, 83(2), 139-149.

Kost, D., Fieseler, C., \& Wong, S. I. (2020). Boundaryless careers in the gig economy: An oxymoron? Human Resource Management Journal, 30(1), 100-113.

Lim, D. H., Song, J. H., \& Choi, M. (2012). Work-family interface: Effect of enrichment and conflict on job performance of Korean workers. Journal of Management and Organization, 18(3), 383-397.

Liu, S. M., Ma, H. Y., Kang, S. J., \& Shen, C. G. (2013). A review of foreign studies on gender-based differences in work-family conflict. Journal of Chinese Women's studies, 5, 116-121.

Lott, Y. (2015). Working-time flexibility and autonomy: A European perspective on time adequacy. European Journal of Industrial Relations, 21(3), 259-274.

Lu, J. G., Brockner, J., Vardi, Y., \& Weitz, E. (2017). The dark side of experiencing job autonomy: Unethical behavior. Journal of Experimental Social Psychology, 73, 222-234.

Mehmood, N., Irum, S., Ahmed, K., \& Sultana, A. (2012). A study of factors affecting job satisfaction (evidence from Pakistan). Interdisciplinary Journal of Contemporary Research in Business, 4(6), 673-684. 
Morgeson, F. P., \& Humphrey, S. E. (2006). The Work Design Questionnaire (WDQ): Developing and validating a comprehensive measure for assessing job design and the nature of work. Journal of Applied Psychology., 91(6), 1321-1339.

Naqvi, S. R., Ishtiaq, M., Kanwal, N., \& Ali, M. (2013). Impact of job autonomy on organizational commitment and job satisfaction: The moderating role of organizational culture in fast food sector of Pakistan. International Journal of Business and Management, 8(17), 92-101.

Ng, T. W., \& Feldman, D. C. (2015). The moderating effects of age in the relationships of job autonomy to work outcomes. Work, Aging and Retirement, 1(1), 64-78.

Nomaguchi, K. M. (2012). Marital status, gender and home-to-job conflict among employed parents. Journal of Family Issues, 33(3), 271-294.

O'Laughlin, E. M., \& Bischoff, L. G. (2005). Balancing parenthood and academia work/family stress as influenced by gender and tenure status. Journal of Family Issues, 26(1), 79-106.

Padhi, M., \& Pattnaik, S. (2017). Role of integration-segmentation on work family interface of insurance sector employees in India. International Journal of Manpower, 38(3), 1114-1129.

Poelmans, S. A. Y., \& Chenoy, R. (2008). Investigating workplace flexibility using a multi-organization database: A collaboration of academics and practitioners. Community Work and Family, 11, $133-137$.

Rihoux, B. (2009). Qualitative Comparative Analysis (QCA) and related techniques: Recent advances and challenges. In Methoden der vergleichenden Politik- und Sozialwissenschaft. VS Verlag für Sozialwissenschaften

Saari, L. M., \& Judge, T. A. (2010). Employee attitudes and job satisfaction. Human Resource Management, 43(4), 395-407.

Sakamoto, Y., \& Spinks, W. (2008). The impact of home-based telework on work-family conflict in the childcare stage. Journal of E Working, 2(2), 144-158.

Saragih, S. (2011). The effects of job autonomy on work outcomes: Self efficacy as an intervening variable. International Research Journal of Business Studies, 4(3), 203-215.

Schaubroeck, J., \& Ganster, D. C. (1991). The role of negative affectivity in work-related stress. Journal of Social Behavior and Personality, 6(7), 319-330.

Schaufeli, W. B., \& Taris, T. W. (2014). A critical review of the Job Demands-Resources Model: Implications for improving work and health. In G. F. Bauer \& O. Hammig (Eds.), Bridging occupational, organizational and public health: A transdisciplinary approach (pp. 43-68). New York: Springer.

Schieman, S., \& Glavin, P. (2008). Trouble at the border? Gender, flexibility at work, and the work-home interface. Social Problems, 55(4), 590-611.

Schiff, M., \& Leip, L. (2019). The impact of job expectations, workload, and autonomy on work related stress among prison wardens in the United States. Criminal Justice and Behavior, 46(1), 136-153.

Shockley, K. M., Shen, W., Denunzio, M. M., Arvan, M. L., \& Knudsen, E. A. (2017). Disentangling the relationship between gender and work-family conflict: An integration of theoretical perspectives using meta-analytic methods. Journal of Applied Psychology, 102(12), 1601-1635.

Su, T., Chen, C. H., Li, Z. H., Pan, W., \& Feng, J. M. (2019). The relationship between work-to-family conflict and job attitude: With meta-analytic evidence in cross-cultural perspective. Chinese Journal of Management, 16(11), 1650-1660.

Ten Brummelhuis, L. L., \& Bakker, A. B. (2012). A resource perspective on the work-home interface. American Psychologist, 67, 545-556.

Wang, Y. L., \& He, S. Z. (2008). A review of work-family conflict from the cross-cultural perspective. Business Review, 20(5), 21-27.

Wegman, L. A., Hoffman, B. J., Carter, N. T., Twenge, J. M., \& Guenole, N. (2018). Placing job characteristics in context: Cross temporal meta-analysis of changes in job characteristics since 1975. Journal of Management, 44(1), 352-386.

Wessels, C., Schippers, M. C., Stegmann, S., Bakker, A. B., van Baalen, P. J., \& Proper, K. I. (2019). Fostering flexibility in the new world of work: A model of time-spatial job crafting. Frontiers in Psychology, 10(3), 1-13.

Westover, J. H., \& Taylor, J. (2010). International differences in job satisfaction: The effects of public service motivation, rewards and work relations. International Journal of Productivity and Performance Management, 59(8), 811-828.

Woodside, A. G., Sullivan, D. P., \& Trappey, R. J. (1999). Assessing relationships among strategic types, distinctive marketing competencies, and organizational performance. Journal of Business Research, 45(2), 135-146. 
Yang, L., Fu, C., Zhao, X., Chen, L., Yan, H. L., \& Zhang, Y. (2015). Mediating effect of job burnout on the relationship between work-family conflict and subjective well-being. Chinese Journal of Clinical Psychology, 23(2), 330-335.

Zhang, X., Fan, Y., Huang, M. P., \& Yan, J. (2013). Formation mechanism model construction of organizational commitment based on self-determination theory: When autonomy need becomes the dominant need. Nankai Business Review, 16(6), 59-69.

Zhao, C., \& Gao, Z. H. (2014). Work-family conflict among new generation knowledge-workers: An analysis based on interactions of demographics differences. Journal of Psychological Science, 37(4), 944-949.

Zhao, X., \& Namasivayam, K. (2012). The relationship of chronic regulatory focus to work-family conflict and job satisfaction. International Journal of Hospitality Management, 31(2), 458-467.

Zuo, J. (2004). Shifting the breadwinning boundary: The role of men's breadwinner status and their gender ideologies. Journal of Family Issues, 25(6), 811-832.

Publisher's Note Springer Nature remains neutral with regard to jurisdictional claims in published maps and institutional affiliations.

Jing Wu is a PhD candidate in School of Economics and Management of Southwest Jiaotong University. Her research interest is organizational behavior and human resource management. In particular, she is interested in exploring the motivation of gig workers.

Jianan Zhou is a Professor in School of Economics and Management of Southwest Jiaotong University. Her research interest is corporate governance and executive motivation. 